\title{
Antropologia, imagens e ARTE. Um Percurso Reflexivo a partir de GeORges Didi-Huberman
}

\author{
Etienne Samain ${ }^{1}$ \\ UNICAMP, SP, Brasil
}

As fronteiras entre historia da arte, imagens e antropologia foram felizmente abaladas no decorrer das duas últimas décadas. Na virada cognitiva visual da qual participamos, essas ciências - Antropologia e Historia da Arte - outrora distintas, vão redescobrindo a natureza e os horizontes de seus próprios comę̧os. Neste ensaio, o autor retraça algumas das etapas de sua própria descoberta e exploração das relações entre antropologia, imagens e arte, remetendo às importantes contribuições de Gregory Bateson, Claude Lévi-Strauss, Alfred Gell, Hans Belting, William J.T.Mitchell. Abre, em seguida, um novo espaço crítico, que conduz à obra humanistica de Georges Didi-Huberman, quando, na linhagem de Aby Warburg e de Walter Benjamin, esse filósofo e historiador da arte trata de situar as imagens e o saber visual como sendo um campo privilegiado de questionamentos sobre nossa história, apelos e gritos para tomar posição em nome do porvir de nosso planeta.

Palavras-chave: saber visual, antropologia, história da arte, Georges Didi-Huberman

Cada obra é apenas a tecelagem de outras obras já vistas Julia Kristeva

As reflexões sobre a imagem são numerosas e de ordens as mais diversas. Apresento neste ensaio um percurso pessoal nesse sentido. Gostaria de começar falando-lhes de um pequeno livro que acabei de receber, intitulado Précis de photographie à l'usage des sociologues (Breve manual de ensino da fotografia para o uso dos sociólogos). Os autores, doutores em Sociologia (em Lausanne, na Suíça e em Nantes, na França), são respectivamente Michael Meyer e Sylvain Maresca (2013), esse último que conhecemos melhor no Brasil.

O que oferece esse livro de cem páginas, publicado em outubro de 2013?

$1 \mathrm{O}$ autor é professor titular aposentado do Programa de Pós-Graduação em Multimeios. Instituto de Artes da Universidade Estadual de Campinas (UNICAMP), SP, Brasil. Contato: etienne.samain@gmail.com 
Primeiro, uma retrospectiva crítica com relação aos usos da fotografia nas publicações sociológicas desde a fundação dessa ciência quando, - no momento em que nascia o daguerreotipo -, Auguste Comte, em 1831, cunhava o termo de sociologia. Um estado da arte, então, que lembra as publicações pioneiras do American Journal of Sociology (de 1898 a 1916) e dá ênfase aos trabalhos de Franz Boas, Bronislaw Malinowski, Gregory Bateson e Margaret Mead, Erving Goffman, Douglas Harper.

No entanto, logo depois, por parte dos autores, é proposta esta questão um tanto enigmática: "Será que algo novo está para aparecer na área"?

No segundo capítulo (o mais importante, penso), outra reflexão: a de uma abordagem crítica, desta vez, das questões metodológicas e técnicas para se utilizar das imagens no campo das ciências sociais. Os autores insistem:

$\mathrm{Na}$ medida em que as imagens se tornam uma parte integrante e essencial da cultura das jovens gerações, numa sociedade - ela também - invadida pelas imagens, é imperativo que se entre no coração do assunto, abordando as questões metodológicas e técnicas a fim de dar aos estudantes de sociologia ferramentas práticas para utilizar as imagens com pertinência e rigor" $(2013: 8)^{2}$

No terceiro capítulo, os autores nos remetem a importantes questões epistemológicas levantadas pelo fazer fotográfico no campo das ciências sociais. Reflexões essas que me permito revisitar com as minhas próprias palavras em torno de três perguntas:

Até onde vai nosso direito de olhar para os outros, pensando definir suas identidades através de nossas fotografias?

O que significa "observar" tratando-se de entender os homens e as culturas? E ainda: O que observar? As "estruturas que conectam os seres vivos" [Gregory Bateson]?; "O Studium e o Punctum" [Roland Barthes] ou, melhor, "O modo maior ou o modo menor da realidade" [Albert Piette], isto é, esse conjunto de pequenos detalhes, aparentemente sem importância, que, todavia, encontram-se carregados de todo um peso de significações?

O que pensar das relações de singularidade e de complementariedade de que se nutrem texto e imagem, na elaboração do discurso antropológico, lembrando o belo texto de Ernst Gombrich:

Se considerarmos a comunicação do ponto de vista privilegiado da linguagem, vamos descobrir que a imagem visual é sem igual no que diz respeito a sua capacidade de despertar, que sua utilização para fins expressivos é problemática e que, reduzida a si-mesma, a possibilidade de se igualar à função enunciativa da linguagem lhe falta radicalmente (1983:323)?

As reflexões sobre as imagens nas artes e nas ciências humanas (Sociologia, Antropologia, História, Pedagogia) são múltiplas. Poderíamos, aliás, pensar em uma outra questão muito atual: a das reconfigurações das imagens, isto é, das novas figuras, das novas imagens (de cultura) que as tecnologias eletrônicas e digitais proporcionam, em termos estetizantes e éticos.

2 As obras aqui citadas, tem tradução minha e foram originariamente escritas em francês ou foram lidas por mim em sua versão francesa, conforme apontados na bibliografia. 


\section{De Gregory Bateson e Claude Lévi-Strauss ...}

Não poderia me aventurar em um diálogo entre Antropologia, Imagens e Arte sem deixar claras algumas das minhas opções acadêmicas. Para ser breve, diria que, de uma formação clássica em Antropologia Social no Museu Nacional do Rio de Janeiro, passei rapidamente a me interessar por questões referentes ao que chamamos hoje de "Antropologia Visual", talvez por ter tido a chance, no intervalo, de me debruçar sobre essas produções e montagens intelectuais, eminentemente visuais e cinematográficas, que são os mitos das sociedades indígenas ágrafas com as quais convivi. ${ }^{3}$

Se, fundamentalmente, no decorrer de mais de quinze anos, pensei poder dar minha contribuição à Antropologia Visual (mergulhando, para tanto, na História da Antropologia Visual e nos legados visuais de alguns importantes antropólogos), paralelamente, caminhava em direção a campos de questionamentos mais amplos que, desta vez, procuravam conjugar os diversos meios da comunicação humana como sendo outros tantos modos lógicos singulares de se pensar o mundo e como sendo outras tantas maneiras de se organizar socialmente.

Não haverá de se admirar se se acrescentar que minha feliz "bricolagem" acadêmica deve muito a Claude Lévi-Strauss de um lado, a Gregory Bateson do outro.

Lévi-Strauss (1908-2009), notadamente no seu admirável capitulo 1 do Pensamento Selvagem (1970), me fez descobrir que existem dois modos distintos, dois níveis estratégicos de pensar e de fazer ciência: o primeiro aproximadamente ajustado ao da percepção e da imaginação, e o outro mais afastado desta intuição sensível. Lévi-Strauss situava a arte na intersecção desses dois níveis estratégicos, na intersecção da razão e da imaginação.

De Gregory Bateson (1904-1980), guardei essa frase simples: "No decorrer da minha existência, coloquei as descrições de tijolos e de jarras, de bolas de sinuca e de galáxias numa caixinha e, ali, deixei-as repousar. Numa outra caixa, coloquei coisas vivas: os caranguejos do mar, os homens, os problemas de beleza e a questão das diferenças. É o conteúdo da segunda caixa que a mim interessa"(Bateson 1980:17). Acrescento - pois é importante realçar o que vou dizer: na caixa das coisas vivas, coloquei as imagens .

Com o recuo que hoje tenho, percebo que algo acontecia no final da década de noventa, algo que não identificava na época. É verdade que já não me interessava tanto pelas questões relativas à natureza da imagem (fotográfica, cinematográfica, videográfica, infográfica), nem pelas funcionalidades diversas das máquinas de imagens em termos cognitivos. Se se falava ainda de Antropologia visual, uma outra preocupação, muito mais profunda, emergia: a necessidade de que distintas ciências do saber humano (no caso, a História da Arte e a Antropologia) haviam de redescobrir a natureza e os horizontes de seus próprios começos. Reaprender, senão a conjugar, pelo menos a reconhecer suas singularidades e suas complemementaridades. Para tornar mais claro o meu propósito, ofereço dois textos que se recortam e que poderão nos esclarecer: o primeiro, de um historiador da arte (Belting), o outro, de um antropólogo (Gell), ambos nossos contemporâneos.

3 Os índios Kamayurá (Alto Xingu, em 1977-78) e Urubu-Kaapor (Cabeceiras do Rio Gurupy - MA, em 198081). Ver Samain (1991). 
Hans Belting, ao falar da "História da Arte" enquanto "ciência" e "disciplina", prefaciava a versão francesa de seu livro intitulado O fim da História da Arte? (1985) nesses termos:

Esta disciplina sobrevive mesmo se ela perdeu sua vitalidade e procura o sentido de sua própria atividade [...] As fronteiras entre a arte, a cultura e as pessoas que a produzem são novamente questionadas [...] A arte é, doravante, entendida como um sistema entre outros de compreensão e de reprodução simbólica do mundo [...]. Vencer a fronteira entre a Arte e seu "pano de fundo" social e cultural requer instrumentos diferentes e objetivos de interpretações diversos. Somente uma atitude de experimentação pode deixar entrever novas respostas (1985:10-16, passim).

Será que devo acrescentar que o mesmo Belting nos ofereceu, desde então, um importante livro intitulado Pour une anthropologie des images (2004)?

Paralelamente, entender-se-á o que motivava o antropólogo inglês Alfred Gell, pouco antes de sua morte, na sua última obra L'Art et ses agents, une théorie anthropologique (2009). Na perspectiva dos sistemas de "troca" (Marcel Mauss) ou de "parentesco" (Claude Lévi-Strauss), Gell escrevia:

Assim como os seres humanos, as obras [de arte] pertencem a famílias, linhagens, tribos, povos. Entram em relação umas com outras, bem como com as pessoas que as criam e as fazem circular enquanto objetos individuais. Pode se dizer que elas se casam e dão luz a obras que levam o marco de seus ancestrais. As obras de arte são manifestaçôes da 'cultura' no sentido coletivo da palavra, e são, como os seres humanos, seres cultos. Até o presente, nunca tomamos em conta a dimensão coletiva das obras de arte. Para abordar corretamente esta questão, é necessário recorrer a outro registro (1998: 186-187).

Haverá de descobrir melhor como esses autores e outros participavam de um zeitgeist que William John Thomas Mitchell (1986) anunciava ao cunhar o conceito de Pictorial Turn [Virada Pictórica]. O historiador de arte de Chicago não procurava dar uma etiqueta à aparição das mídias pretensamente 'visuais', a televisão, o vídeo e o cinema. Observava que existia uma especificidade do pictorial turn própria a nossa época. Escrevia:

Segundo penso, a imagem [...] chegou a constituir um assunto urgente e próprio de nossa época, não somente no campo político e na cultura de massa [...] mas nas reflexões mais gerais relativas à psicologia humana e ao comportamento social, ou ainda às estruturas do saber (p.20). [...] Pleiteio a favor de um relativismo estrito e rigoroso considerando o saber como uma produção social, como um diálogo entre diferentes versões do mundo, diferentes línguas, diferentes ideologias e diferentes modos de representações (pp. 84-85).

Esta rápida evocação de relações novas que iam se criando entre Antropologia, Imagens e Arte, é suficiente para que, agora, possamos centrar nossa atenção sobre a figura e algumas das vertentes heurísticas propostas por Georges Didi-Huberman, porta-voz e exegeta da obra do pensador alemão Aby Warburg que, nos inícios do século vinte, em Hamburgo, já explorava este campo das interrelações entre Antropologia, Imagens e Arte, antecipando toda uma reflexão atual. 


\section{... Aby Warburg e Georges Didi-Huberman}

Não por acaso, foi em Hamburgo que, em 2002, encontrei pela primeira vez Georges DidiHuberman. Ele apresentava, no 6th Congresso Internacional Word and Image, a conferência de abertura "Words, Winds, Image: Aby Warburg and the Imaginary Breeze in the Quattrocento", precisamente na cidade onde nasceu Aby Warburg (1866-1929), um judeu-alemão, primogênito de uma família secular de banqueiros, pai dessa moderna "ciência das imagens", a que chamamos "iconologia", um historiador da Arte, um antropólogo. Nessa ocasião tive a oportunidade de descobrir os lugares onde Warburg trabalhava: sua famosa biblioteca elíptica. Tomei conhecimento, pouco depois, de sua Atlas Memnosyne, uma surpreendente obra publicada pela primeira vez em alemão em 2000 (Warburg:2000) e, paralelamente, o livro mestre de DidiHuberman L'image survivante. Histoire de l'art et temps des fantômes selon Aby Warburg (DidiHuberman : 2002) ${ }^{4}$.

Falei de Claude Lévi-Strauss, de Gregory Bateson, de Aby Warburg. Vocês têm as chaves para entender como, dez anos depois de ter cruzado o fantasma de Warburg em Hamburgo, podia nascer o livro Como pensam as imagens (Samain:2012) que organizei com a participação de nove colegas e amigos. Devo apenas mencionar a importante dedicatória deste livro: "A Georges Didi-Huberman, por nos fazer descobrir Aby Warburg e muito mais". Um agradecimento e uma responsabilidade.

Não lhes falarei aqui de Aby Warburg ${ }^{5}$ mas, com Georges Didi-Huberman, tentarei levantar algumas pistas reflexivas sobre a imagem (sobre as imagens) enquanto elas são lugares singulares de um pensamento original que as habita. Antes, gostaria de situar brevemente no tempo esse historiador da arte, filósofo e ensaísta, e oferecer outras pistas para adentrar sua obra gigantesca.

Didi-Huberman nasceu em Saint Etienne, na França, em 1953. Sobre sua infância e adolescência, ele se explica: "Eu sou o filho de um pintor. Passava horas no ateliê. Limpava os pinceis [...] ia de carona ver as galerias de arte contemporânea em Paris; [...] adolescente, trabalhava muitas vezes no Museu de Arte Moderna de Saint Etienne, ajudando a documentar, assistindo às montagens de exposição e experimentando visitas comentadas". Ele completa: "Lhes falei do ateliê do meu pai, um espaço para a arte, para a beleza, para o consolo e para a dimensão erótica das imagens. [...] Mas isso representou apenas a metade da minha experiência. A outra metade que, literalmente, 'quebrava' a primeira, encontrava-se na biblioteca materna: eram todas as imagens da guerra, as imagens dos campos que vi e revi com essa dificuldade de entender [...] no inverso absoluto de toda beleza, no inconsolável, na dimensão enlutada das imagens...” (Revista

\footnotetext{
4 Esse livro foi traduzido por ocasião da primeira vinda de GDH ao Brasil (no final de maio de 2013: Simpósio "Imagens, Sintomas, Anacronismos", organizado pelo Programa de PG em Artes Visuais da UFRJ). Assinalamos que, na mesma ocasião, foram publicadas duas outras obras de peso em torno do legado de Aby Warburg: uma coletânea (traduzida do original alemão [1998] por Markus Ediger) dos ensaios do próprio Aby Warburg. A renovação da Antiguidade pagã. Contribuições científico-culturais para a história do Renascimento europeu (Warburg 2013) e o importante livro Aby Warburg e a imagem em movimento (Michaud 2013).

5 No Como pensam as imagens, ofereço um longo texto "Aby Warburg. Mnemosyne. Constelação de culturas e amputheta de memórias" (2012: 51-80), onde procuro conduzir o leitor, de um lado, a uma visão de conjunto da pessoa e da obra de Aby Warburg, e, de outro, à análise minuciosa da última Prancha do Atlas Mnemosyne. Uma temática, aliás, que retrabalhei numa outra contribuição "As Mnemosyne(s) de Aby Warburg. Entre Antropologia, Imagem e Arte" (2011: 29-51), na qual tento, desta vez, descrever as etapas heurísticas pelas quais passei para chegar à análise da referida Prancha 77 do Atlas.
} 
Vacarme, n³7, 2006, pp.5-6).

Georges Didi-Huberman é descendente de judeu-alemão. Seu avô Jonas, em 20 de abril de 1944, morria em Auschwitz. Cerca de setenta anos depois, em junho de 2011, GDH visitava pela primeira vez o campo de extermínio onde seu avô morreu. Um mês depois dessa curta viagem, publicava o admirável Écorces (Didi-Huberman:2011). Aconselho muito a leitura desse pequeno texto de 70 páginas, 19 imagens fotográficas (realizadas pelo próprio GDH) e 19 curtos capítulos. Um magnífico exemplo da maneira por meio da qual GDH “pensa por imagens".

O livro inicia-se com estas palavras:

"Pousei três pedacinhos de casca [de bétula] [essas árvores que cercam, hoje ainda, os silêncios de Auschwitz] sobre uma folha de papel. Olhei. Olhei pensando que olhar me ajudaria talvez a ler algo que nunca tinha sido escrito. Olhei os três pequenos fragmentos como se fossem as três letras de uma escrita - anterior a todo alfabeto. Ou talvez, como o começo de uma carta a ser escrita; mas para quem? [...] São três fragmentos arrancados de uma árvore há algumas semanas, na Polônia. Três fragmentos de tempo. Meu próprio tempo em seus pedaços; um pedaço de memória, essa coisa não escrita que procuro ler; um pedaço do presente, aí sob os meus olhos, sobre a página branca; um pedaço de desejo, a carta para escrever, mas para quem?” (2011:9).

Não se pode entrar na obra de GDH sem ter conhecimento deste pano de fundo: a Shoah (a Catástrofe). Toda sua obra leva e levanta um olhar paciente, crítico, poético e político sobre a humanidade, sobre essas Imagens apesar de tudo. Faz-se necessário também descobrir lentamente quais são os pensadores com quais GDH está em constante diálogo. Entre eles, cito Ernst Bloch, Friedrich Nietzsche, Theodor Adorno, Bertolt Brecht, Henri Bergson, Georges Bataille, Carl Einstein, Maurice Blanchot, Gilles Deleuze, Michel Foucault, Giorgio Agamben, Aby Warburg e Walter Benjamin em especial.

De formação, GDH é filósofo e historiador da Arte, atualmente professor na Escola dos Altos Estudos em Ciências Sociais de Paris (EHESS). Ele é, mais profundamente, o detentor de um conhecimento enciclopédico, de uma erudição extraordinária, um pensador que sabe dialogar, provocar e estimular a reflexão, um pesquisador humanista, um intelectual humilde, que, a cada momento, descobre um novo objeto de trabalho. Se ele se interessa fundamentalmente pelas imagens, é, por desdobrá-las, nos apresentando, ao mesmo tempo, as obras de artistas contemporâneos (fotógrafos, videógrafos, cineastas, documentaristas, coreógrafos, músicos, pintores e escultores): Eisenstein, Pier Paulo Pasolini, Roberto Rossellini, Rainer Maria Rilke, Giuseppe Penone, Chris Marker, Harun Farocki, Jean-Luc Godard, Wang Bing, Simon Hantaï, Bertolt Brecht, James Turrell, Agusti Centelles, Christian Boltanski, Alfredo Jaar, Philippe Bazin, Mathieu Pernot, Israel Galván, Pascal Convert, Sarkis, Steve McQueen, James Coleman etc.

GDH dirá: "Creio que todo o meu trabalho está guiado por uma intuição fundamental sobre a imagem, enquanto ato e enquanto processo [...] Diante da imagem devemos convocar verbos para dizer o que as imagens fazem e o que elas nos fazem (onde elas nos tocam), e não apenas adjetivos e nomes para acreditar ter dito o que elas são".

Deve-se acrescentar: GDH é um escritor que, além de dominar os idiomas alemão e francês, sabe honrar essas duas línguas, com suas precisões linguísticas e suas aberturas poéticas. Ele é um coreógrafo das imagens: pensa as imagens, questiona as imagens, deixa-se interpelar pelas imagens. Em poucas palavras: sempre põe as imagens em movimento. Ele é, ainda, um brilhante ensaísta que, assim, se define (Didi-Huberman 2010: 191-192): "Um ensaísta é um 
homem simplesmente preocupado de entender o sofrimento do mundo e de transformá-lo, de remontá-lo em uma forma explicativa, implicativa e alternativa. Ele não constrói nenhuma verdade absoluta, não fabrica nenhuma obra de arte para a atemporalidade da arte".

GDH põe sempre seu leitor em face de um leque de movimentos, de paixões, de questionamentos sobre a história presente de nosso mundo. Entre suas últimas publicações, assinalo os quatro primeiros volumes ${ }^{6}$ (de sete anunciados) de L'Oeil de l'Histoire (O Olho da História), uma clara referência a Georges Bataille e ao seu inquietante livro História do olho.

\section{UMA ARQUEOLOGIA DO SABER VISUAL}

Numa entrevista dada à Marianne Alphant no Centro Pompidou em junho de 2010, GDH confiava "Meu sonho seria o de esboçar o que Michel Foucault fez muito bem com os textos [As palavras e as coisas], isto é, esboçar uma arqueologia do saber visual”.

O que viria a significar tal arqueologia para Georges Didi-Huberman? O que nos indicaria? Quais os caminhos heurísticos e metodológicos que nos sugeriria? Como procuraria nos acompanhar? Eis alguns prováveis caminhos de suas indagações.

Gostaria de refletir sobre as imagens na medida em que são - constitutivamente - fenômenos, acontecimentos, aparições, revelações, epifanias, pequenas luzes que queimam o tecido humano (social) e interpelam (ou não) nosso cotidiano.

Gostaria, também, de olhar para elas e deixá-las nos inquietar na medida em que as imagens não são apenas atos e fatos, mas ainda - na temporalidade que toda imagem carrega - lugares de memórias (lembranças, sobrevivências, ressurgências), revelações de tempos passados, de tempos presentes. Por vezes, até lugares de expectativas (esperanças, prefigurações de tempos que hão de vir, presságios, promessas, desejos).

Gostaria, ainda, de olhar para elas, não apenas como campos de memória, como arquivos vivos e lugares de desejos, mas ainda, como um terreno de questões, de questionamentos sobre nossa história, apelos (às vezes, gritos) que nos convocam a tomar posição em nome da história humana, em nome do porvir de nosso planeta.

Assim, não apenas "pensar a imagem” e, sim, "pensar por imagens”, isto é, aprender a "abrir”, a "desdobrar" as imagens, para, nelas, redescobrir, numa perspectiva aberta por Walter Benjamin, seus profundos e verdadeiros valores de uso (de utilização, de projeto) para o nosso século, em especial nesta virada cognitiva e comunicacional da qual participamos. $\mathrm{O}$ antropólogo, o cientista social, é alguém que não deve apenas ficar ocupado (preocupado) pela descrição, ilustração, registro, pela documentação da história presente dos homens e das culturas; é alguém que, ao realizar todas ou parte dessas tarefas, deve permanecer ocupado (preocupado) em "entender as pulsões e os sofrimentos do mundo, de transformá-los, de remontá-los em uma forma explicativa implicativa e alternativa" (Didi-Huberman 2010:191) .

6 Eis os títulos dos tomos já publicados: Vol. 1: Quando as imagens tomam posição (2009); Vol.2: Remontagens do tempo sofrido (2010); Vol. 3: Atlas ou a Gaia ciência inquieta (2011, traduzido para o português: 2013); Vol. 4: Povos expostos, povos figurantes (2012). 
Somos artistas, antropólogos, sociólogos, historiadores, fotógrafos, videógrafos, amantes das imagens, seres humanos. Levanto esta pergunta: o que faremos das imagens (das imagens dos outros e de nossas imagens) para servir ao nosso século, para pensar nossa história, para fazer viver os homens? E, mais ainda: como faremos delas e com elas, lugares de conhecimentos e de questionamentos, atos de memória, campos de desejos e de futuros?

\section{REFERÊNCIAS}

Bateson, Gregory. 1980. Mind and Nature. A Necessary Unity. Toronto/Nova York, Bantam Books. Versão portuguesa: Mente e natureza. A unidade necessária. Rio de Janeiro: Francisco Alves, 1986.

Belting, Hans. 1985/2007. L'histoire de l'art est-elle finie? Histoire et archéologie drun genre. Paris: Folio. Original alemão: Das Einde der kunstgeschichte? Munique : Deutscher Kunstverlag, 1983.

2004. Pour une anthropologie des images. Paris: Flammarion. Original alemão. BildAnthropologie: Entwürfe für eine Bildwissenschaft. Munique: Wilhelm Fink Verlag, 2001 ; Versão Castelhana: Antropologia de la imagem. Madri: Katz Editores, 2007.

Didi-Huberman, Georges. 2002. L'image survivante. Histoire de l'art et temps des fantômes selon Aby Warburg. Paris: Editions de Minuit. Tradução portuguesa: A imagem sobrevivente. História da arte e tempo dos fantasmas segundo Aby Warburg [Tradução:Vera Ribeiro]. Rio de Janeiro: Contraponto Editora Ltda e Museu de Arte do Rio [MAR], 2013. 2010. Remontages du temps subi. L'oeil de l'Histoire,2. Paris: Editions de Minuit.

2011. Écorces. Paris: Editions de Minuit. Versão brasileira Cascas, in Revista Serrote, no13. São Paulo: Instituto Moreira Salles,2013.

Gell, Alfred. 2009. L'Art et ses agents, une théorie anthropologique. Paris: Fabula/Les presses du réel. Original inglês: Art and Agency. An anthropological theory. Oxford: Oxford University Press, 1998.

Gombrich,Ernst.1983. “L'image visuelle”.Pp.323-349 in L'écologie des images. Paris: Flammarion. Lévi-Strauss, Claude.1970. O pensamento selvagem. São Paulo: Companhia Editora Nacional e Editora da USP. Original Francês: La pensée sauvage. Paris:Plon, 1962.

Maresca, Sylvain e Meyer, Michaël. 2013. Précis de Photographie à l'usage des sociologues. Rennes: Presses Universitaires de Rennes.

Michaud, Philippe-Alain. 2013. Aby Warburg e a imagem em movimento [Tradução de Sibylle Muller]. Rio de Janeiro: Contraponto Editora Ltda e Museu de Arte do Rio [MAR]. Original francês: Aby Warburg et l'image en mouvement. Paris: Macula,1998.

Mitchell, William John Thomas. 2009. Iconologie. Image, Texte, Idéologie. Paris:Les Belles Lettres, 2009. Original inglês:Iconology. Image, Text, Ideology. Chicago: The University of Chicago Press, 1986.

Samain, Etienne.1991. Moroneta Kamayurá. Mitos e aspectos da realidade social dos indios Kamayurá (Alto Xingu). Rio de Janeiro: Ed. Lidador.

.2011. "As Mnemosyne(s) de Aby Warburg. Entre Antropologia, Imagem e Arte". Poiésis (Revista do Programa de PG em Ciências da Arte da UFF),12(17):29-51. Em linha: http:/www.poiesis.uff.br/sumarios/sumario17.php?ed=17)

2012. Como pensam as imagens. Campinas: Editora da Unicamp.

. 2012. "As peles da fotografia: fenômeno, memória/arquivo, desejo".Visualidades

(Revista do Programa de Mestrado em Cultura Visual da Universidade Federal de 
Goiás),10(1):151-164. Em linha: http://www.revistas.ufg.br/index.php/VISUAL/issue/ view/1273/showToc

Warburg, Aby.2000. Der Bilderatlas Mnemosyne (editado por Martin Wanke e Claudia Brink), Berlim: Akademia Verlag, 2o ed. 2002. Disponível em língua castelhana desde 2010: Atlas Mnemosyne. Madri: Ediciones Akal.

2013. A renovação da Antiguidade pagã. Contribuições científico-culturais para a bistória do Renascimento europeu. Rio de Janeiro: Contraponto Editora Ltda e Museu de Arte do Rio [MAR].

\section{Anthropology, pictures and ARTS. A Reflective Journey based on Georges Didi-Huberman}

The boundaries between art history, pictures, anthropology were shaken over the past two decades. During the visual cognitive turn of which we are part, these sciences - Anthropology and Art History - formerly distinct, rediscovered the nature and the horizons of their own beginnings. In this essay, the author outlines some of the steps of his own discovery and exploration of the relationship between anthropology, arts and images, referring to the important contributions of Gregory Bateson, Claude Lévi-Strauss, Alfred Gell, Hans Belting and William J.T. Mitchell. Finally, the author opens a new critical terrain, which leads to the humanistic work of Georges Didi-Huberman. This philosopher and art historian, following Aby Warburg and Walter Benjamin, situates images and visual knowledge as a privileged field of inquiry about our bistory.

Keywords: visual knowledge, anthropology, art history, Georges Didi-Huberman

Recebido em: 2014-02-13

Aceito em: 2014-05-06 